\title{
A Study: Exploring the Feasibility of Developing a Computer Science Online Degree Program at Tuskegee University
}

\author{
Ingrid A. Buckley ${ }^{1} \&$ Hira Narang ${ }^{1}$ \\ ${ }^{1}$ College of Business \& Information Science, Tuskegee University, Tuskegee, Alabama, USA \\ Correspondence: Ingrid A. Buckley, College of Business \& Information Science, Tuskegee University, Tuskegee, \\ Alabama, USA. Tel: 1-334-727-8371. E-mail: ibuckley@mytu.tuskegee.edu
}

\author{
Received: March 14, 2014 Accepted: April 17, 2014 Online Published: May 28, 2014 \\ doi:10.5539/hes.v4n3p48 URL: http://dx.doi.org/10.5539/hes.v4n3p48
}

\begin{abstract}
This paper investigates the feasibility of developing an online degree for a computer science and information technology degree programs. Our motivation is to increase access to quality education with the aim of stimulating growth, attracting new students, and retaining our current student body. A survey was conducted of CS/IT online degrees which are offered completely online. The survey includes various historically black colleges and universities (HBCUs) and majority universities throughout the United States to gain a broad perspective on the current offerings. This study provides comparisons of some majority universities against smaller universities, especially HBCUs in terms of online education. The pros and cons associated with online education are discussed to further understand if it could help us attain our goals. The resource and requirements (infrastructure, software, tools, and training) needed to develop a degree completely online are presented. A wide variety of tools, technologies software programs available in both private and public domain are enumerated and described. A detailed discussion is presented based on our departmental and curricular needs, including a phased implementation strategy for creating undergraduate and graduate degree programs online. A cost and benefit analysis is given to determine roughly, the overall effort of implementing online degrees within the CS Department. Lastly, some recommendations and conclusion based on our findings from the cost benefit analysis is presented. The goal of this work is to provide other institutions pondering the implementation of online courses/degree programs with a holistic understanding of this endeavor in terms of magnitude and cost.
\end{abstract}

Keywords: computer science, information techology, online degree, online course development, online course

\section{Introduction}

Online education has seen dramatic growth over the last few decades. Online education has significantly increased in popularity among students of all ages. Online learning allows universities to increase their enrollment by creating distance learning programs. Distance learning programs provide a flexible and convenient way for students to further their tertiary education. Online courses can be accessed by students at any time without decreasing the quality of education that is achieved in on-site degree programs or online courses. Today, online learning has become a mandatory addition to many universities degree programs because, it affords students from varying backgrounds and circumstances the opportunity to further their education (Koller, 2013). Many universities have leveraged the benefits of online education and students are responding positively to this change and reaping the many benefits.

Computer Science is one of the most expansive, innovative, and adaptive areas of knowledge today. As expected, online Computer Science degree programs have gained much popularity over the past decade, mainly to leverage the benefits that technology realizes, but also, to utilize the very principles that are taught in these programs.

Majority universities such as Harvard, Carnegie Mellon, Nova South Eastern University offer all levels of computer science courses online. Many of these universities, have gone a step further, and now offer free online computer science courses through MOOCs (Pappano, 2012), which provide another platform for academics to share information. MOOCs allows anyone, anywhere, with access to the internet to register, watch lectures, submit assignments and projects, and communicate with instructors via e-mail. HBCUs have not quite caught up to the competition, with regards to offering online degree courses or programs. Online education requires different resources than is typically required for on-site degree programs. In particular, special tools, 
infrastructure, networks and databases are needed to successfully develop an online course/degree program. Over time, the benefits of an online degree program generally exceed the initial startup costs.

The paper is organized in the following manner. Section 2 provides motivation behind this work, and a comparison of universities that offer CS/IT degrees completely online. Section 3 discusses some pedagogical pros and cons of online education. Section 4 presents infrastructure needs, educational tools, commercial and open source software for managing online programs, along with various institutions and companies that develop online course content. Section 5 suggests an approach to develop an online program. Section 6 provides a cost benefit analysis. Section 7 provides recommendations and the paper concludes with section 8 .

\section{Motivation}

Our Dean, in the college of Business and Information Science, was interested in exploring the possibility of developing online courses or complete online degrees for Computer Science/Information Technology disciplines. His motivation was to assess whether the Computer Science Department could reverse the decreasing trend of enrollment for the last few years, and to see if the increase in the enrollment in Information Technology majors could be feasible due to the hands-on nature of the IT discipline. The Dean wanted to first understand if such an undertaking could turn out to be financially and practically viable due to the dependence of the undergraduate degrees on other disciplines and departments. A Bachelors of Science degree is usually awarded after three or four years of college study in Computer Science/Information Technology and also includes standard courses in Mathematics, Humanities, Natural and Social Science, and Business. This means, developing a complete online degree requires university-wide effort.

\subsection{Computer Science Online Programs at Various Universities}

The United States has over 3500 degree granting universities. Approximately 132 universities offer computer science online courses and programs at the undergraduate and graduate level. Many of these universities offer some computer science courses online, however, typically, not all of their computer science courses in their undergraduate and graduate program are offered completely online. There are approximately 104 historically black colleges and universities (HBCUs) in the United States, including public and private, two-year and four-year institutions, medical schools and community colleges. Only $27 \mathrm{HBCU}$ offer doctoral programs and 52 provide graduate degree programs at the Master's level. At the undergraduate level, 83 of the HBCUs offer a Bachelor's degree program and 38 of these schools offer associate degrees. Roughly $10 \%$ of the HBCUs offered online degrees in 2013 in varying disciplines (American School Search, 2014).

Our findings show that most HBCUs that offer computer science courses/degrees either do not offer them completely online, or offer them only in a blended format. In the blended course, students are required to attend classes to complete specific components of the course, while other units of the course can be completed online. In a blended degree program, students complete a portion of the degree online and the remainder in a traditional format.

Perhaps one of the reasons why HBCUs do not generally offer complete online degrees could be that they require substantial finances, infrastructure and support services to offer, maintain, and continuously upgrade courses needed for online audience, and the changing trends in online technology. The other reasons could be the accruable benefits from this venture to universities with a larger student population, serves and benefit a larger audience and could further benefit those institutions by attracting more students and retaining them.

\section{Advantages/Disadvantages of Online Education}

Online Education was not originally popular; however, the internet and the ubiquity of technology have impacted online learning positively. Online Education is responsible for increased student enrollment and access to higher education from anywhere across the globe. There are some fundamental reasons that support the viability of online education. First, millennials typically choose non-traditional education to start and advance their careers while completing and furthering their education. Second, the down-turn in the US economy forced people to upgrade/change their career through online educational programs.

With the increased popularity of online education, there are notable advantages and disadvantages that result when compared to the traditional education system. The advantages are classified in 4 distinct categories (Kumar, 2010), they are:

\section{Convenience:}

- No commuting/traveling time, saves on time and transportation cost

- No geographic location restriction 
- No learning pace limitation, students learn at their own pace and study at their convenience

- No verbal expression constraint, express yourself in writing rather than verbally

- Course work and instructions can be customized to any field and subject area

- Increased access to resources, easier to include guest experts or students from other institutions

\section{Reduced cost:}

- No travel and housing costs

- Student can work at his/her job while taking classes

- No need for physical facilities such as classrooms and associated furniture, parking etc.

\section{Flexibility/Technology:}

- Capability to access course work from anywhere

- Provides opportunity for students to learn and utilize new technologies

\section{Additional benefits:}

- No discrimination among students due to race, sex, sexual orientation, religion, etc.

- Higher probability for equal participation from all classmates, outspoken students cannot dominate verbal discussions

- No visa and immigration problems

The disadvantages are also broken into 4 categories, they include:

\section{Inadequate Social Interaction:}

- Communication is done through e-mail, chat room or discussion groups

- No face-to-face dialog with instructor

- No campus atmosphere to create physical social interaction

\section{Technology Cost and Scheduling:}

- Computer boot-up time, software programs, and connection to Internet

- Students may be required to learn new or enhanced computer and troubleshooting skills

- High-speed Internet cost

- Delayed response to student questions from instructor

\section{Effectiveness of Assessments:}

- Classroom tools may be difficult to apply and memory testing is not an effective measure of learning in any environment

- Difficult to measure course results

\section{Problems for Instructors:}

- Traditional instructors accustomed to handouts may have a difficulty adopting the online system and software

- Student must be self-motivated and disciplined in order to complete their work on time which can affects student retention

Note that some of the disadvantages listed above are also experienced in the traditional education system. Typically, unmotivated students who do not show up for class usually do not perform well. Exposing students to new technology and troubleshooting issues is an additional benefit, as it allows them to master the technology they have to work with, these skills will serve them well beyond the online classroom (Kumar, 2010). Faculty members who have rooted themselves in the sanctuary of campus based face to face education are the most vocal critics of online education.

\section{Infrastructure and Software Needs}

Below we provide details of the infrastructure and software needs that are required to develop an online degree program. 


\subsection{Infrastructure}

All educational endeavors are systems, made up of various interconnected components. In distance education, understanding how the entire system of course development and delivery occurs, and how these systems link to services and other components are important aspects of ensuring effectiveness and quality.

In order to create high quality videos, a controlled and well equipped environment is necessary to record online classes. Video quality is imperative, therefore, high definition, scalable and high performance cameras are needed to create rich content. Audio equipment is equally important in any learning environment. Communication has to be clear and succinct without delay and distortion, because students rely heavily on excellent communication to carry out their studies remotely.

Additionally, SMART Boards (SMART, 2013) have been adopted by many universities for they combine the simplicity of a whiteboard with the power of a computer. The SMART Board interactive whiteboard allows you to deliver dynamic lessons, write notes in digital ink and save your work - all with the simple touch of a finger. The SMART Board uses an integrated SMART projector which limits shadows and projects quality image, making visuals crisp and bright.

Servers are required to store and retrieve recorded videos and any other course material. Power Supply system sources should always be available to power the server and its associated sub-systems (cameras, SMART Board and mikes) to ensure that content is not lost. Additionally, proper lighting is needed in the recording classroom to ensure that videos are aesthetically pleasant.

\subsection{Software and Tools}

Online education relies heavily on special tools and technologies in order to create a successful and functional learning environment. There are a variety of tools on the market that provide the resources needed by instructors and students. Wimba (Wimba, 2014) and Blackboard (Blackboard, 2014) are two widely used products for supporting online learning.

Wimba provides educators and students the ability to build relationships by combining interactive technologies with instructional best practices. Wimba contains many capabilities which include support of audio, video, application sharing, and content. Wimba has advanced features such as polling, whiteboarding, presenter on-the-fly, resizable chat areas and participant lists, usage analytics tools, and MP3 and MP4 downloads enable further dynamic interaction between students and educators. Wimba uses Voice over IP to afford natural communication; it modulates tone of voice, captures body language and conveys the natural enthusiasm and interest of the professor.

Wimba affords flexibility in that, a wide variety of cameras used on computer systems or devices will be compatible with Wimba. This allows students to obtain the benefits of online instruction without the hassle of incompatibility issues. This reduces help desk support for students. Additionally, Wimba provides SSL encryption for classroom traffic thus reducing disruption from outside intruders whilst upholding the standards of learning.

Wimba can be easily integrated with Blackboard through Blackboard Collaborate. Blackboard Collaborate (Blackboard Collaborate, 2014) manages pre-session planning and post-session recording management tools that support the entire instructional cycle. Blackboard collaborate allows students and professors to view classroom recordings on a desktop or easily convert for download or streaming to any mobile device to meet the needs of on-demand active learners.

Blackboard has already been adopted by Tuskegee University. Blackboard provides institutions the ability to develop and implement a learning management system that impacts every aspect of education. Blackboard allows professors to engage students in exciting new ways, reaching them on their terms and devices - and connecting more effectively, keeping students informed, involved, and collaborating together.

ANGEL Learning Management Suite (LMS) (ANGEL LMS, 2014) is a tool for creating virtual learning environments for online learning. A learning management system (LMS) is a software application for the administration, documentation, tracking, and reporting of training programs. ANGEL is used to offer hybrid or blended (web-enhanced) classes. In addition to creating courses, and adding content, ANGEL also has features such as pattern recognition of online student activity, assessment tools that measure learning outcomes against class objectives.

\subsection{Companies Offering Online Course Development Support}

Developing an online course requires a different way of planning, presenting and delivering course content to 
distant learners. Online course development requires new skills. Several institutions and companies provide assistance with online course development. Higher Education institutions offering courses online to meet increasing demand often times, procure outside help (Hobson, 2014) to develop or design their digital curriculum.

The American Distance Education Consortium (ADEC) is a non-profit distance education consortium. The consortium was developed to encourage the creation and delivery of quality, economical distance education programs and services to diverse audiences. ADEC utilize subject matter specialists and information resources to share knowledge and content with learners. ADEC offers assistance locally, regionally, nationally, and internationally, their focus includes helping institutions with (ADECO, 2013):

- Design for active and effective learning

- Distance learning designs should consider context, needs, content, strategies, outcomes and environment

- Support the needs of learners

- Develop and maintain the technological and human infrastructure

Accel Media (Accel Media, 2014) provides training and services centered around online course development and assessment. They convert existing traditional courses into online courses, create instructional curriculum design, voice-over narration, art and graphics. Additionally, Accel Media provides technical support to users, host, manage and update online courses. Mindflash (MindFlash, 2013) uses existing training content to build interactive web-based courses in a timely fashion. They include features and tools for training, deployment, and progress management for online courses. TestOut (TestOut, 2014) offers interactive and intuitive tools that support effective communication and delivery of technical courses such as networking, CISCO certification and security online.

\subsection{Open-Source Software for Online Course Development}

There are several open source software available for online course development and for customizing courses using predesigned course templates. An existing course can be enhanced with the addition of embedded videos, links and tasks. These software are most suitable for descriptive or non-computer science courses. However, they can allow for the development of needed computer science courses within the available framework. The two most famous are: WebQuest (WebQuest, 2014), and HyperInquiry (HyperInquiry, 2014).

WebQuest (WebQuest, 2014) uses a bottom up approach to develop non-technical courses online. A WebQuest is an inquiry-oriented lesson format in which most or all the information that learners work with comes from the internet. It consists of embedded videos, links, assessment, and information surrounding a topic. WebQuest has a variety of different course templates that can be used by instructors to quickly and effectively develop an online course.

HyperInquiry (HyperInquiry, 2014) uses an inductive approach to design non-technical courses online. HyperInquiry is based on a three phase model which encapsulates concept, interpretation of data and application of principles. This approach encourages students to understand, extrapolate, and apply information by coaching them to identify patterns for learning different topics.

iTunes $\mathbf{U}$ (Apple, 2014) is a new application software created by Apple, that gives instructors the capability of creating courses for students on an IPAD. The courses can be created using multiple formats such as audio videos, presentation, documents, and iBooks for ipads. It allows students to integrate with iBooks and other apps thus allowing them to keep abreast with courses. iTunes $U$ app stores documents, notes, highlights, and bookmarks up to date across multiple devices.

Moodle (Moodle, 2014) is an open-source alternative to Blackboard. Moodle is a free learning management system which provides functions for assignment submission, discussion forum, files download, grading, online quizzes and announcement.

\section{Developing an Online Degree Program}

Based on demand and the changing dynamics of universities globally, and the goal to attract more students, it may be feasible to offer online degrees completely online at the undergraduate and graduate level. There are some significant foundational units that must be implemented before the development of an online degree program begins.

The Computer Science Department at Tuskegee University offers 3 undergraduate degrees: Computer Science 
(CS), Information Technology (IT) and Information Science (IS). The CS Department will offer a new Master of Science degree in Information Systems and Security Management in the fall 2014. This graduate program aims to prepare highly-qualified professionals with both Information Systems Management and Information Security Management expertise. Currently, both the undergraduate and graduate degree programs are offered onsite in the traditional classroom format. The CS department recognizes the need to provide alternative access to their degree programs to attract new students, stimulate growth and retention of our current student body. One mission of the Computer Science Department is to offer online courses using a phased approach starting in fall 2015.

\subsection{Implementation Strategies}

Given the challenges (McAlister, Rivera, \& Hallam, 2001) of implementing an online program for our curricula it is more feasible to develop an online degree program in segments. This objective can increase access to quality education that supports students' lifestyles. A total of thirty-four (17 undergraduate and 17 graduate) courses from our current curricula will be offered in an online format in phase 1 and phase 2 of our mission. All of the undergraduate service level and graduate courses will be made available in the spring and fall semesters in two modes, online and the in-class version.

Phase 1 will begin with the development of the freshman level undergraduate and first year graduate courses. 9 undergraduate and 8 graduate courses will be developed in phase 1 during the summer semester; these courses will then be offered in the following fall. Each course will be monitored to identify inadequacies; the results will be collected and analyzed to improve the courses in the subsequent spring. The same approach will be adopted for the remaining undergraduate and graduate courses which will be offered in successive phases. Figure 1 shows a model of the phased step-wise model for implementing an online undergraduate and graduate degree program.

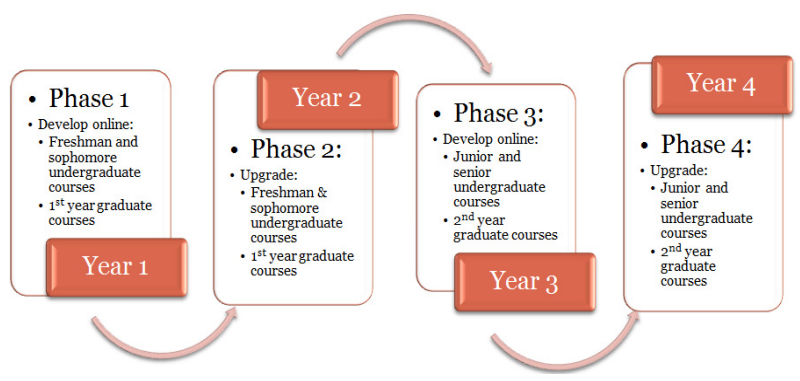

Figure 1. Phased implementation approach

\section{Cost and Benefit Analysis}

Our primary aim is to offer quality and flexible education that is consistent with the current educational climate. More universities and community colleges are offering blended and online courses to meet the needs of the students they target. In order for institutions to remain competitive it may be beneficial to consider meeting the needs of diverse students. Several established universities have highlighted the benefits that they have experienced with the launch of distance learning/online education. Some of the benefits include:

- Increased access to online education to students globally

- Online course materials can be accessed 24 hours a day every day

- Increased flexibility to students

- Encourages students of all ages to interact thus, increasing the diversity of opinions

- Reduces additional costs for transportation and accommodation

- Students communicate with their instructor online

- Provides students access to specialized degree courses

Additionally, online courses allow for the recruitment of students from a variety of unique backgrounds, this includes: homebound individuals, adult students, returning students, special training for corporate employees and executives who wish to further their knowledge by enrolling in any of our many specialized security courses. Online courses are geared towards student needs on a broader platform, this can increase student enrollment. 


\subsection{Initial Technology and Infrastructure Needs}

There is an increasing range of user interfaces, physical devices and supporting infrastructure that facilitate online learning. It is important to meet with different information and communications technology (ICT) infrastructure providers (DELL, CISCO, and INTEL) to get an estimate of the overall cost to develop an online program on a scale that is consistent with the requirements (The Center for Digital Education and Converge, 2013) (Blinco, Mason, McLean, \& Wilson, 2004). Technology and infrastructure needs can become quite costly, however, there is the option of procuring the services of companies that offer the technology, server space, databases storage and online facilities that will support our online courses.

Most universities use some form of course management system, such as Blackboard for example. Integrating video lectures into the existing course management software used in your university is encouraged to reduce cost Video lectures are useful as students can access them at any time. However, this feature will significantly impact the budget, because it requires additional infrastructural resources, both in hardware, software, storage and communications. Additionally, if the cost to employ external help is not feasible or too expensive, another option is to source the expertise of the faculty and staff to build and manage a useful infrastructure. Generally, the infrastructure and technology needs in most universities may include a CLOUD, some workstations and the appropriate software (operating system and applications) to develop and manage the online program.

\subsection{Online Course Development and Faculty Training}

Effective online course development, management and training will determine the success of online courses. Departments who are thinking about this, or just beginning to embark on this new endeavor, may need to initially utilize the professional expertise from companies and institutions with proven track record and specialization in the required areas. The strength of online education is not only contingent on the medium it uses but in the way it is used. Similarly, online course development and training is provided by companies and other institutions at a cost. It is important to train faculty and staff members by sending them to various workshops, conferences, and professional seminars. Strong consideration must be given to training the faculty specifically for online teaching as well as the time allocated for training. Instructional design support and guidelines can help instructors get acclimated to this new form of teaching. The trained instructors can be utilized as mentors for new faculty members for future training or professional development efforts.

\subsection{Recruitment and Marketing}

Recruiting students is a major factor that currently impacts the enrollment in the traditional programs in many Computer Science departments, and most definitely will impact online student enrollment. Recruitment and marketing determines how to reach a specific audience and market new programs and online courses offered. It can be difficult to reach a new market, and this may require considerable effort and support to accomplish this feat. There are three key principles that govern successful recruitment: communication, persuasion, and consummation (acquiring a student). One approach is to use social media outlets (Blogs, Facebook, Twitter, and Instagram) to help market and reach potential students. Another approach is to procure the services of companies who have experience with recruitment and marketing for online educational programs (Hobson, 2014). Some companies host virtual online fairs (Hobson, 2014) to recruit potential students.

\subsection{Budgetary Requirements}

The estimated cost of infrastructure, software, time and effort involved in developing our curricula will run close to one million dollars. Our estimation includes the cost of five (5) blade servers for a Cloud, 40 workstations for course development and testing, labs, faculty training and development, faculty release time for course development, software and other miscellaneous costs. This estimated cost only involves one department; therefore, the cost for developing online degrees for an entire university will cost several millions. This budget will increase dramatically if Tuskegee University takes on the responsibility to offer all of the undergraduate and graduate degrees/programs completely online.

\section{Recommendations}

We recognize the substantial initial start-up cost associated with online education and the dependence of the undergraduate degree on supportive departments. Most curriculums span several disciplines and require courses from varying departments such as humanities, mathematics, natural and social science. Some of these departments may not be equipped or ready to offer online courses. Institutions that have the finances and the need to grow their student base can look into creating online degree programs. There are some challenges that must be considered at the undergraduate level: 
- First, online students expect the convenience of taking all classes in a 4 year undergraduate program online.

- Secondly, undergraduates take courses such as Math, English, History, Chemistry and Biology, all of which are offered in other colleges; and these colleges and departments may not offer these courses online.

- Third, undergraduates are not always familiar with the pace of university level courses, and may not find it easy to keep up with their courses or manage their time efficiently.

- Fourth, computer science courses can be rigorous and abstract in nature.

- Fifth, classes should not be full of complicated and tech-heavy features and try to incorporate many different concepts just because they are online. Simplicity can sometimes go a long way.

However the challenges associated with online degree can be addressed as follows:

- All major, non-major and required courses in the 4 year undergraduate degree program must be offered online.

- Offering an undergraduate degree has to be a university wide effort. All disciplines which teach core courses that are required in the curriculum for undergraduates must offer these courses online as well.

- Online students must be guided using various online medium (Skype, IM) to ensure that they have the support they need to successfully complete courses. This means that, online advisors are necessary to assess student performance and intervene before their performance drop below the set threshold (Pock, 2011).

- Instructors must utilize intuitive tools and approaches to convey abstract principles and concepts. This requires the use of some of the tools discussed in section 4 such as ANGEL.

- Frequent interaction between students, and between students and their instructors, is key to academic and social integration. This is not only true in traditional settings, but online as well, which can promote persistence.

Offering an online graduate degree is a viable option due to its non-dependence on other departments and will enable a department to diversify the number of channels/medium to deliver its graduate degree to students globally. Graduate students are generally more motivated, and experienced especially after completing the four years for an undergraduate degree. A master's degree generally offers a saturation of courses from one discipline. As a result, all the courses are typically offered by one department, this makes it easier to create and manage such courses online since they do not require intervention from other colleges. However, instructors still face a challenge, because offering advanced courses online require innovative approaches to convey knowledge as well as tools. Advanced courses often cover challenging topics which require skilled delivery.

\section{Conclusion}

We recognize the changing and learning needs of students, and the benefits of creating online degree programs. These benefits allow universities to expand and diversify their student body as well as their degree programs. However, initial start-up cost including infrastructure, faculty training and maintenance, must be thoroughly considered. Although there are many advantages in offering online degrees in terms of attracting more students, both residential and non-residential, the costs and benefits have to be properly weighed and a feasibility study of such a venture has to be done. We must consider the feasibility and overall cost of attracting new students in the face of competition from institutions with well-established online programs. These costs must be properly evaluated before jumping on the band wagon. A cautious and phased approach is recommended as outlined in section 5 .

We are aware of the initial cost, challenges and maintenance associated with offering online courses and degrees completely online. However, in order to advance in pedagogy, it will be worthwhile in the long run to explore the online direction. The benefits of online education include facilitating existing residential students, who may complete their degrees earlier because of the availability of certain online courses. This can also benefit them when they are away on summer internships or cannot afford to physically attend school due to financial or other unavoidable reasons.

In our case, offering an undergraduate online program will require university wide resources and effort which will cost millions of dollars. However an online graduate program is most feasible for our department, as this program would not be as large as its undergraduate counterpart and does not require the help from other 
departments. We could easily utilize some of the open-source software systems and tools, our current infrastructure and faculty expertise to support and cater to our graduate students.

\section{Acknowledgments}

The authors are thankful to Dr. T. Sara, Dean, College of Business and Information Science for suggesting this study and to Dr. C. L. Chen for critiquing our internal proposal from which this paper was derived.

\section{References}

Accel Media. (2014). We Build Online Courses. Retrieved from http://www.accelemedia.com/about.html

ADECO. (2013). The American Distance Education Consortium. Retrieved from http://www.adec.edu/

American School Search. (2014). Colleges and Universities. Retrieved from http://www.american-school-search.com/colleges/hbcu

ANGEL LMS. (2014). ANGEL Learning Management Suite. Retrieved from: $\mathrm{http}: / /$ www.angellearning.com/products/lms/whats_new_74.html

Apple. (2014). iTunes $U$. Retrieved from http://www.apple.com/education/ipad/itunes-u/

Blackboard Collaborate. (2014). About Blackboard Collaborate. Retrieved from http://www.blackboard.com/platforms/collaborate/overview.aspx

Blackboard. (2014). About BB. Retrieved from http://www.blackboard.com/

Blinco, K., Mason, J., McLean, N., \& Wilson, S. (2004, July). Trends and Issues in E-learning Infrastructure Development [White paper]. $\quad$ Retrieved from http://www.jisc.ac.uk/uploaded_documents/Altilab04-infrastructureV2.pdf

Center for Digital Education and Converge. (2013). Smart Infrastructure [Special Report]. Retrieved from http://images.erepublic.com/documents/CDE13+SPQ1_V.PDF

Hobson. (2014). Higher Ed Institutions. Retrieved http://www.hobsons.com/education-professionals/higher-education/

HyperInquiry. (2014). Instructional \& Learning Strategies. Retrieved from http://www.southalabama.edu/coe/bset/dempsey/isd613/summer04/unit/wq/hyperinquiry.html

Koller, D. (2013, June). How online education can create a global classroom. Retrieved from http://edition.cnn.com/2013/06/21/business/opinion-koller-education-petersburg-forum

Kumar, D. (2010). Pros and Cons of Online Education. Manuscript, North Carolina State University, Raleigh, NC, USA.

McAlister, M. K., Rivera, J. C., \& Hallam, S. F. (2001, July). Twelve important questions to answer before you offer a web based curriculum. Online Journal of Distance Learning Administration, 4(2). Retrieved from http://www.westga.edu/ distance/ojdla/summer42/mcalister42.html

MindFlash. (2013). Easy Online Training. Retrieved from http://www.mindflash.com/

Moodle. (2014). About Moodle. Retrieved from http://docs.moodle.org/26/en/About_Moodle

Pappano, L. (2012, November). The Year of the MOOC. The New York Times. Retrieved from http://www.nytimes.com

Pock, R. (2011, March). Cyber-School: The Challenges of Teaching and Learning Online from One English Instructor's Perspective. Retrieved from http://bcis.pacificu.edu/interface/?p=320

SMART. (2013). Smart Boards. Retrieved from http://smarttech.com/smartboard

TestOut. (2014). LabSim Educational Solutions. Retrieved from

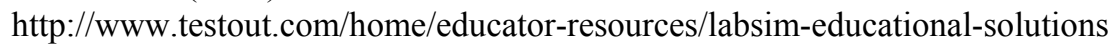

WebQuest. (2014). What is a WebQuest? Retrieved from http://webquest.org/index.php

Wimba. (2014). Wimba Classroom for Higher Education. Retrieved from http://www.wimba.com/solutions/higher-education/wimba_classroom_for_higher_education 


\section{Copyrights}

Copyright for this article is retained by the author(s), with first publication rights granted to the journal.

This is an open-access article distributed under the terms and conditions of the Creative Commons Attribution license (http://creativecommons.org/licenses/by/3.0/). 